\title{
Assertiveness, Machiavellism, Lack of Protection from Manipulations and Psychological States of Teachers and Students
}

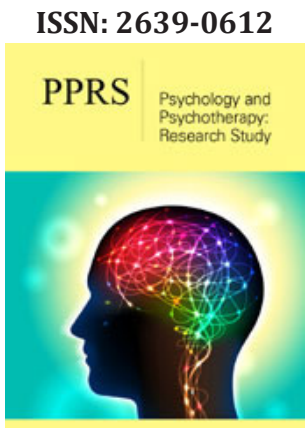

*Corresponding author: Sheinov VP, Republican Institution of Higher Education, Belarus

Submission: 覘 September 01, 2019 Published: 侮 November 07, 2019

Volume 3 - Issue 1

How to cite this article: Sheinov VP. Assertiveness, Machiavellism, Lack of Protection from Manipulations and Psychological States of Teachers and Students. Psychol Psychother Res Stud. 3(1).PPRS.000551.2019.

DOI: 10.31031/PPRS.2019.03.000551

Copyright@ Sheinov VP, This article is distributed under the terms of the Creative Commons Attribution 4.0 International License, which permits unrestricted use and redistribution provided that the original author and source are credited.

\author{
Sheinov VP* \\ Republican Institution of Higher Education, Belarus
}

\begin{abstract}
The article shows, teachers are insufficiently protected from manipulative actions from students. Assertiveness helps protect from manipulation and has a negative effect on personal anxiety and a positive effect on motivation to succeed. The degree of personal exposure to manipulation is higher among students than among teachers. As objects of manipulation, students become more aggressive than their teachers, but the latter experience anguish more often. Students get more positive emotions from their own manipulations as compared to their tutors. Teachers feel more ashamed of their manipulations than students.
\end{abstract}

Keywords: Assertiveness; Machiavellism; Exposure to manipulation; Psychical states; Anxiety; Motivation; Teachers; Students

\section{Introduction}

Assertiveness is the ability of a person to stand up for his or her rights with confidence and dignity, without infringing upon the rights of others. Assertive behavior is one that is open, direct and lacks the aim of offending others [1]. Assertive behavior is a constructive manner of interpersonal communication which serves as an alternative to destructive types of behavior-manipulation and aggression [2]. This alternative is particularly relevant since manipulative relationships are very common in modern society [3-8] and, unfortunately, have a tendency to becoming more and more widespread. Social disruptions of the last decades have contributed to the growth of manipulative relationships. They have had an adverse impact on social consciousness as well as on the consciousness of an individual with a considerable part of society [9]. Overall moral decay is taking place amid the ever-increasing power of money. This can be seen, in particular, from the significant increase in corruption which is one of the forms of manipulative relationships. As a result, an increasing number of our fellow citizens turn to manipulation and, correspondingly, more people fall victim to their manipulation. At the same time, the psychical states of objects and subjects of manipulative influences remain unstudied.

Consequently, the following questions arise:

1. Does the assertiveness of an individual help to protect him or her from manipulation and, on the whole, does the assertiveness of an individual rule out his or her submissive (passive) behavior?

2. What psychical states are experienced by the subjects and objects of manipulative influences?

3. Based on the hope of instilling assertiveness, it appears reasonable to continue exploring the construct of the assertiveness of an individual.

\section{Used Method}

For the purposes of researching and evaluating assertiveness, an author's method was used to measure assertiveness, the reliability and validity of which has been proven [10]. For the purposes of studying the degree of personal exposure to manipulative influences, 
an author's test was used, the reliability and validity of which has been proven [8]. For the purposes of evaluating psychical states, experienced by the objects and subjects of manipulation, an author's questionnaire was used, which was drawn up on the basis of sentences, uttered in the author's report during the second All-Russian scientific conference. The psychology of psychical states. Evaluation of the subject's disposition to manipulation (Machiavellianism) was carried out with the help of Machscale-a test by R. Christie and F. Geis, which was adapted [11] to the Russian-speaking society. Subjects' achievement motivation or failure avoidance motivation was determined with the help of Mehrabian's questionnaire [12]. Evaluation of personal anxiety with the help of C. Spielberger's Test-Anxiety Inventory (TAI) [13]. Subjects' self-assessment of interpersonal relationships, behavior, activities, emotions and feelings was done by the means of a selfevaluation test [14]. All respondents filled out the questionnaires of the above-mentioned methods anonymously (under the cipher). The qualities under evaluation were revealed to the subjects along with the testing results. The subjects of the testing were 116 university and college professors, who attended advanced training courses at the Department of Psychology and Pedagogical Mastery of the Republican Institute of Higher Education, 84 teachers and 143 students from 3 colleges, located in Minsk (2) and in Bobruisk (1).

\section{Mathematical processing of the results}

Mathematical processing of the testing results was carried out by a data analysis software package SPSS 18.00 which was used in psychology and social sciences [15]. At all stages of the research, testing results were examined for compliance with a certain distribution law under one-sample Kolmogorov-Smirnov criterion. Calculation of the Z-statistics and the related error probability $\mathrm{p}$ showed that the distribution of all studied variables corresponds with a normal distribution. This allowed us to use parametric methods for statistical analysis. Normal distribution of testing results is an indication that selection is a representative population cross-section [16]. Thus, the representativeness of selections at all stages of the research has been proven by statistical analysis. Accuracy inspection of average value variations of studied variables was carried out with the help of t-criterion for independent selections. Depending on the obtained values under Levene's criterion, two-tailed significance of t-criterion was determined by the assumption of equality or inequality of variances.

\section{The Result and their Discussion}

\section{Assertiveness and protection from manipulation}

When an assertive individual stands up for his or her rights with confidence, it must contribute to protection from manipulative influences. If that is so, then the indicators of individuals' assertiveness must correlate negatively with their indicators of exposure to manipulation. This assumption was originally confirmed in a research [10] for employees of commercial firms, teachers, members of youth orthodox brotherhoods ( $N=394)$. In the present research, we have established the same fact for healthcare workers: $r=-0,339, p<0,001$. Therefore, it is shown that the assertiveness of an individual helps to protect him or her from manipulation. Previously [10] by the means of theoretical analysis of the studied notions, it was established that assertiveness must rule out submissive (passive) behavior.

In particular, it was shown that:

1. These types of behavior cause different results for subjects who are using them.

2. These types of behavior are described by fundamentally different models of psychological influences which cause them.

3. They are carried out by different types of transactions. Since it is typical for the subject's passive behavior to be exposed to manipulation, the established fact of protection from manipulation of an assertive subject provides experimental proof of the previously made theoretical conclusion that assertiveness rules out submissive (passive) behavior.

\section{Teachers and student's assertiveness}

In conformity with the testing results, the distribution of respondents according to behavioral type turned out as follows: among the university and college professors, assertive ones account for nearly $60 \%$, passive- $25 \%$, aggressive-15\% (among the college students: assertive-54\%, passive-19\%, aggressive-27\%). Assertive males-university and college professors-account for more than 1, 5 times those of females. Whilst the average assertiveness among men $(68,92)$ is a bit higher than the average assertiveness among women $(68,53)$, this difference (for the selection at hand) is statistically insignificant. Nevertheless, earlier on [10], in a larger representative selection with 1,500 subjects, it was shown that the stated difference between females and males is accurate ( $p$ $=0,01$ ). Richmond V \& McCroskey V [17] came to the conclusion that students have more trust in professors who they perceive as assertive [17]. And this has a positive effect on the quality of education. Therefore, the assertiveness of a teacher redounds to a more effective teacher-student interaction.

The above-stated estimate, which shows that a significant number of teachers are not assertive, also indicates that there's room for self-improvement of teachers in acquiring assertive behavior skills. In the work of Hill A [18] the effectiveness of training sessions for university professors aimed at helping them to develop assertive skills was proven. Training sessions boost teachers' selfconfidence and extend the usage of assertive behavior techniques; it's important to retain acquired skills no fewer than 6 months after having completed the training. Teachers and students' assertiveness correlates differently with the self-esteem of each of them. Teachers' self-esteem doesn't correlate with any of the sub-scales of the selfevaluation test while students' assertiveness correlates positively with the Interpersonal relationships, interaction box: $r=0,452, p$ $=0,020$. This is particularly important for the younger generation, because this box contains such valuable qualities as politeness, sincerity, tolerance, accountability, demandingness and etc. 
Machiavellism and exposure to manipulation of teachers and students

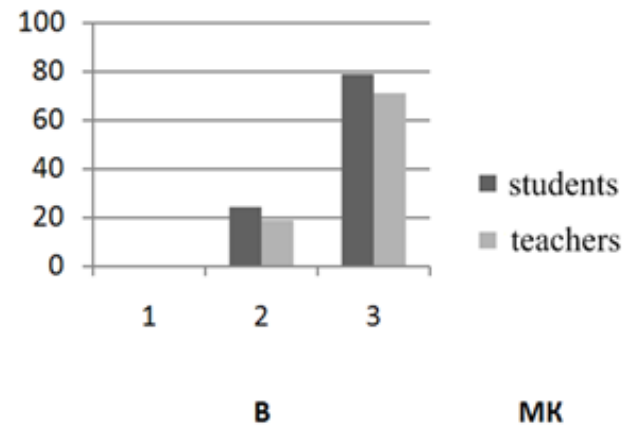

Figure 1: Exposure to manipulation and Machiavellianism among teachers and students.

B-The average testing result (exposure to manipulation), MK the average Machiavellianism.

In the studied selection, the average exposure to manipulation among teachers 0,42 . It means that in $42 \%$ of cases of manipulative influences on the part of students, they reach their indecent goals. Female teachers are better protected from manipulations in comparison to their male colleagues. The average exposure to manipulation among women (raw score 18,71) is statistically significant with $\mathrm{p}=0,01$ below the corresponding number among men $(21,08)$. The issue of exposure to manipulation among teachers is crucial for the quality of education, because teachers often fall victim to manipulative attacks from dishonest students [8,19]. All the more so, the present research shows that (Figure 1) students are more exposed to manipulation than teachers: Machiavellianism among students $(78,65)$ is higher than that of teachers $(70,88)$. But at the same time, students (raw score 24.39) are more exposed to manipulation than teachers (19.06). The stated differences are statistically significant with high accuracy: the difference between teachers and students in the degree of exposure is significant with $\mathrm{p}<0.001$, while disposition to manipulation is $\mathrm{p}<0.001$. This confirms the conclusion we arrived at earlier, that manipulators are exposed to manipulation as well [8].

Lower Machiavellianism among teachers corresponds to the pattern of Machiavellianism vanishing with age, which was previously established by a series of authors [8]. In the previous work [8] it was established that exposure to manipulation among adults is unrelated to Machiavellianism, which means that Machiavellianists are as exposed to manipulation as anyone else. In the present research, our aim was to find out whether or not this provision is applicable for 16-17-year-old teenagers. It has been established that it is not, in fact, applicable: the correlation between exposure to manipulation and Machiavellianism turned out to be statistically significant $(\mathrm{p}=0,01)$ and relatively high $(\mathrm{r}=-0$, 496). That is to say, teen Machiavellianists (in our case 16-17-yearold college students) are much better protected from manipulation than their peers. The validity of this conclusion for a different teenage contingent need to be confirmed by a respective research.

\section{Assertiveness, personal anxiety and achievement motivation}

The correlations between these variables are shown in (Table 1). The data from Table 1 implies that for university and college professors as well as for college students, assertiveness statistically significantly negatively correlates with personal anxiety and positively with achievement motivation. This is quite in line with the essence of assertiveness: assertive individuals stand out because of their high self-esteem and assertion of rights. The average personal anxiety among male teachers $(44,33)$ is within the norm $(31-45)$, although close to its upper edge, among females exceeds it $(48,47)$. This difference is statistically significant $(p=0,021)$. On the whole, in the tested group of teachers, failure avoidance motivation prevails, with it being more evident among females and this difference has high statistical significance: $p=0,001$. Apparently, big work responsibility that teachers bear leads to cautiousness and, as a result, to heightened anxiety and prevailing failure avoidance motivation. The established correlations between PA, FAM and age add some validity to the obtained results. Personal anxiety appears to have inverse correlation with achievement motivation: the higher the former, the lower the latter and this correlation is sufficiently strong $(r=-0,487, p=0,007)$, which is quite predictable. Personal anxiety, showing small tendency to increase with age, can be explained ( $r=0,288, p=0,130)$ : stressing over family (children, parents, etc.), personal well-being and so one, which intensifies with age.

Table 1: The correlations between assertiveness and personal anxiety (PA) and achievement motivation or failure avoidance motivation (FAM).

\begin{tabular}{|c|c|c|c|c|c|c|}
\hline \multirow{2}{*}{} & \multicolumn{2}{|c|}{ University Professors } & \multicolumn{2}{c|}{ College Professors } & \multicolumn{2}{c|}{ College Students } \\
\cline { 2 - 7 } & $\mathbf{r}$ & $\mathbf{p}$ & $\mathbf{r}$ & $\mathbf{p}$ & $\mathbf{r}$ \\
\hline PA & $-0,673^{* * *}$ & 0,000 & $-0,373^{*}$ & 0,041 & $-0,500^{* *}$ & 0,009 \\
\hline FAM & $0,470^{* * *}$ & 0,000 & $0,441^{* * *}$ & 0,002 & $0,440^{*}$ & 0,024 \\
\hline
\end{tabular}

\section{Psychical states of objects and subjects of manipulation}

Psychical states of objects and subjects of manipulation have only begun to be studied.

In the present work, this matter is researched for college professors and students in a wider context, than their interaction during the learning process would allow.

All respondents filled out the questionnaires anonymously (under cipher), 3 questionnaires per person: 
1. Mach-scale;

2. Test B: Evaluation of the degree of exposure to manipulation;

3. The questionnaire on psychical states, experienced by objects and subjects of manipulation.

The participants as objects of manipulation are supposed to choose from the following possible psychical states which are enumerated in the questionnaire:

1. Frustration;

2. Irritation;

3. Indignation;

4. Anger;

5. Confusion (If you had asked, I would have done it);

6. Depression;

7. Resentment (I will never forgive);

8. Self-Destructive Behavior (I deserve it);

9. Carelessness (As long as I'm fine);

10. Suspicion (I need to be more careful);

As subjects of manipulation, participants were to determine whether or not they experience the following psychical states:

11. Satisfaction;

12. Enjoyment (because manipulation was successful);

13. Determination (that's what I should always do);

14. Feeling superior to others;

15. Shame (I shouldn't have done it).

Comparison of the frequency of answers, given by teachers and students (Figure 2), shows that students as objects of manipulation experience a higher total of negative states (see bar chart-total 1-9) than teachers. Also, students more often than teachers experience aggressive states (anger, resentment, irritation, indignation) while teachers as objects of manipulation more often than students experience states characterized as suppressed: frustration, confusion, self-destructive behavior, depression and suspicion. Students as objects of manipulation more often than teachers experience the state of carelessness, and it makes them more exposed to manipulation. Comparison of the degree of expressiveness of psychical states of girls and boys as objects of manipulation has shown that the existing differences between them are within the statistical margin of error, except for the state of carelessness boys' rate is 2 times higher compared to that of girls $(0,27)$, and this difference is significant at $\mathrm{p}<0.05$. This result corresponds with the fact that boys, in general, are more careless than girls. This also explains why women are less exposed to manipulation, because the more careless you are, the more you are exposed to manipulation. The bar chart in Figure 2. Shows that students experience a higher amount of positive emotions from manipulation in comparison to teachers, in total (total 11-14) and separately for each psychical state (satisfaction, enjoyment, superiority). Teachers more often than students feel ashamed of their manipulations. The data from Table 2. also shows that students as subjects of manipulation, use manipulations which are connected to their positive states of superiority, satisfaction, enjoyment and determination to act the same way in the future. And, as a result, high and close correlation with the positive states' total.

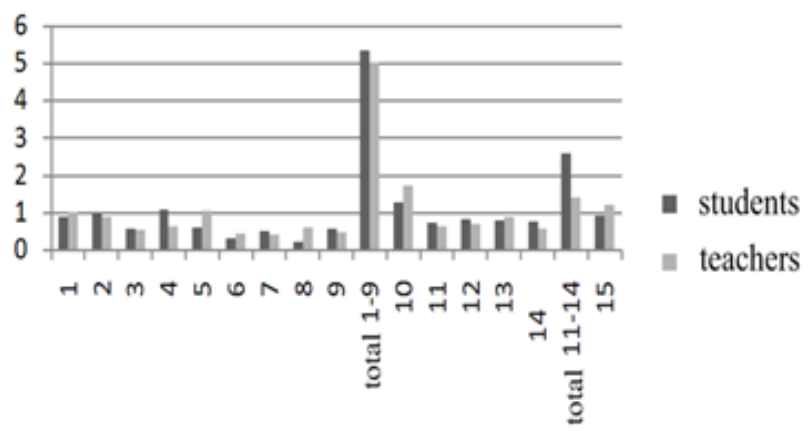

Figure 2: Psychical states of teachers and students as objects of manipulation.

1. Frustration,

2. Irritation,

3. Indignation,

4. Anger,

5. Confusion,

6. Depression,

7. Resentment,

8. Self-destructive behavior,

9. Carelessness,

10. Suspicion,

11. Satisfaction,

12. Enjoyment,

13. Determination,

14. Superiority,

15. Shame.

Table 2: The correlations between the subjects of manipulation machiavellism and his psychical states.

\begin{tabular}{|c|c|c|c|c|}
\hline \multirow{2}{*}{ Psychical State } & \multicolumn{2}{|c|}{ Students } & \multicolumn{2}{|c|}{ Teachers } \\
\hline & $\mathbf{r}$ & $\mathbf{p}$ & $\mathbf{r}$ & p \\
\hline Satisfaction & $0.363^{* * *}$ & 0.000 & $0.339^{*}$ & 0.050 \\
\hline Enjoyment & $0.343^{* * *}$ & 0.001 & 0.244 & 0.172 \\
\hline Determination & $0.239^{*}$ & 0.024 & - & - \\
\hline Superiority & $0.449^{* * *}$ & 0.000 & - & - \\
\hline Positive states' total & $0.297 * * *$ & 0.000 & 0.300 & 0.090 \\
\hline Shame & $-0.231^{* *}$ & 0.002 & $-0.414^{*}$ & 0.017 \\
\hline
\end{tabular}


Teachers as subjects of manipulation, use manipulations which positively correlate (not as strongly as in case of studentsMachiavelli) only with the state of satisfaction and the positive states' total. It is gratifying that both teachers and students feel ashamed of their manipulations, but, in fact, in a much lesser degree than when it comes to positive emotions. The latter is easily explained: otherwise, they would not use manipulation. Apparently, the feeling of shame experienced by teachers is due to lower Machiavellianism.

The presented data shows that the process of manipulation causes a more significant amount of positive emotions for students in comparison to teachers subjects of manipulation. It might also be one of the reasons why average Machiavellism among students is higher than that among teachers.

\section{Conclusion}

1. Teachers (on the whole) are insufficiently protected from manipulative influences on the part of dishonest students. Disposition to manipulation is higher among students than among teachers.

2. The assertiveness of an individual helps to protect him or her from manipulation. Among the university and college professors, assertive one's account for nearly $60 \%$.

3. For university and college professors as well as for college students, assertiveness negatively correlates with personal anxiety and positively- with achievement motivation.

4. Failure avoidance motivation prevails among teachers, with it being more evident among females.

5. Students are more exposed to manipulation than teachers and the latter should take it into consideration.

6. Teenage Machiavellism (16-17-year old's) contributes to protection from manipulative influences.

7. Students as objects of manipulation experience a higher total of negative states (see bar chart -total 1-9) than teachers, also, students more often than teachers experience aggressive states while teachers as objects of manipulation more often than students experience states characterized as suppressed.

8. The differences between psychical states of boys and girls as objects of manipulation are identified only in regard to the state of carelessness.
Students experience a higher amount of positive emotions from manipulation in comparison to teachers, as they more often than students feel ashamed of their manipulations.

\section{References}

1. Meshcheryakov B, Zinchenko B (2004) The big dictionary of psychology. Prime-euroznak, USA, p. 672.

2. Bishop S (2006) Develop Your Assertiveness. Kogan, United Kingdom.

3. Fromm E (1992) Man for himself. Kollegium, Belarus, p. 54.

4. Shostrom E (1967) Man, the manipulator. The inner journey from manipulation to actualization. APA PsycNET p. 192.

5. Rumshina L (2000) An empirical study of teachers' behavioral styles. Psychology questions 1: 142-150.

6. Sheinov V (2012) Developing a questionnaire for the evaluation of the degree of exposure to manipulative influences. Psychology questions 4: 147-154.

7. Sheinov V (2014) Developing of a test on assertiveness that meets both reliability and validity requirements. Psychology questions 2: 107-116.

8. Sheinov V (2012) Machiavellianism. Harvest, Belarus, p. 416.

9. Kulikov L (2013) Social determinants of mass attitudes and states/ psychology of psychical states: Topical theoretical and practical issues/ second all-Russian scientific conference. Russia, pp. 100-106.

10. Sheinov V (2014) The typology of behavior in cases of direct and indirect influences. Vestnik (bulletin) of the peoples friendship university of Russia. Psychology and pedagogics series №3.

11. Znakov V (2000) Machiavellism: Psychological property of a person and it's method of research. Psychological journal 21(5): 16-22.

12. Greben N (2010) Psychological tests for psychologists. Sovremenaya shkola, Belarus, p. 480.

13. Karelin A (2006) The big encyclopedia of psychological tests. Eksmo, Russia, p. 414.

14. Stolyarenko L (2003) Fundamentals of psychology: A workshop. Fenix, Russia, p. 704.

15. Nasledov A (2005) SPSS. Computer analysis of data in psychology and social sciences. Spb, Piter, Russia, p. 416.

16. Anastasi A, Urbina S (1990) Psychological testing. Spb, Piter, Russia, p. 688.

17. Richmond V, Mc Croskey J (1990) Reliability and separation of factors on the assertiveness-responsiveness measure. Psychological Reports 67: $449-450$.

18. Hill EH (1977) Development of an assertiveness training module for college-level instructors.

19. Tarelkin A (2006) Students' manipulative influence on teachers in pedagogic communication. Visheishaya shkola, Belarus, 2: 29-33. 